\title{
UTILITY AND IMPACT OF QR CODES AND BARCODES IN SCHOLARLY JOURNALS
}

\author{
Mahdi Lotfipanah ${ }^{* 1}, 2$ \\ ${ }^{1}$ Department of Medical Ethics and Law, Reproductive Biomedicine Research Center, Royan \\ Institute for Reproductive Biomedicine, ACECR, Tehran, Iran \\ 2 Department of Medical Library and Information Sciences, Royan Institute for Reproductive \\ Biomedicine, ACECR, Tehran, Iran
}

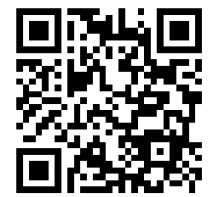

DOI: https://doi.org/10.29121/granthaalayah.v8.i5.2020.55

Article Type: Research Article

Article Citation: Mahdi Lotfipanah. (2020). UTILITY AND IMPACT OF QR CODES AND BARCODES IN SCHOLARLY JOURNALS. International Journal of Research GRANTHAALAYAH, 8(5), 51-54. https://doi.org/10.29121/granthaa layah.v8.i5.2020.55

Received Date: 06 May 2020

Accepted Date: 26 May 2020

Keywords:

QR Code

Barcode

Academic Journals

Scholarly Journals

Quick Response code

Identifier

\begin{abstract}
In 1994 a squared two-dimensional barcode was invented by Toyota Company which changed and speed up the concept of tracking and identification. They chose its name QR which stands for Quick Response code. Quick Response codes can convey data such as show a geographical location, make a phone call, link to a simple text, link to a website or template email, access to a portable document format (PDF), display an image, link and download a specific application on a mobile device or WiFi login. Academic journal leaders should notice that QR code as a unique shaped matrix code is increasingly being used by prestigious publishers and scientific journals. But has been ignored by eastern scientific journals and academic institutes for many years. As the author checked all English Iranian journals, no Iranian academic publication or publisher has and uses QR code or even barcode on their websites or on their journal covers till 16 Dec 2019. In this review, the author aimed to explore the use of QR codes specifically for academic publications, identify perceptions towards their use and any information that has been encountered during implementation.
\end{abstract}

\section{INTRODUCTION}

In 1994 a squared two-dimensional barcode was invented by Denso Wave [1], a former subsidiary company of Toyota and a regular member of the Japan Robot Association [2], which changed and speed up the concept of tracking car components during manufacturing and distribution[3] It was a big solution for the business, services and, systems in the company for more work efficiency. That's why they chose its name QR which stands for Quick Response code. It is made up of black and white squares and dots technology with the ability to contain many information in a $10^{\text {th }}$ of the space and omnidirectional scanning capabilities instead of old barcode scanners used in the eighties [4]. In the same decade by the early 1990s commercial networks, business campaigns and, enterprises began linking to the World Wide [5] and QR codes as free of cost available technology could be created online from a range of websites. Quick Response codes can convey data such as show a geographical location, make a phone call, link to a simple text, link to a website or template email, access to a portable document format (PDF), display an image, link and download a specific application on a mobile device or Wi-Fi login [6]. Plus, the availability of

(C) 2020 The Author(s). This is an open access article distributed under the terms of the Creative Commons Attribution License, which permits unrestricted use, distribution, and reproduction in any medium, provided the original author and source are credited. 
Utility and Impact of QR Codes and Barcodes in Scholarly Journals

smartphones in the 1990s [7] and camera phones since the beginning of the 21 ${ }^{\text {st }}$ century [8] changed the world of communication and networking. These tools and gadgets finally led QR codes being applied to a wide range of applications including advertising [9], payment and management such as transportation [10], the commercial processes involved in promoting and selling and distributing a product or service. However, with the advent of technology and increasing the number of mobile phones (smartphones) equipped with cameras that enable reading QR codes can access the internet and address automatically by simply reading a URL link or PURLs encoded in the QR code. The use of these codes is also gradually are increasing in the world especially in the Middle East and Africa from a low of 12 percent in 2017 to 18 percent in 2018 [11]. It has become widespread in many fields. In this review, we aimed to explore the use of QR codes specifically for academic publications, identify perceptions towards their use and any information that have been encountered during implementation.

\section{VALUE AND ADVANTAGES OF QR CODE}

The value of QR code in education has been proved [12] and this international QR code as an International standard code (ISO/IEC18004) could increases reading and learning levels by visual learning [13][14]. In addition, applying QR code allows more flexibility for accessing and sharing materials [15], anywhere, any time, and may be used for anything and everything free of charge as Denso Wave has released the patent into the public domain. So, the main advantage is its versatility. Saving time and money are other benefits. As mentioned in other high profile studies, QR code provides opportunities for further interaction and could encourage readers and researchers to read more and attract them to study online and could more effectively motivate researchers to search much information that is available more easily [16][17]. This information reported and proved by an editorial on the introduction of QR code [18]. QR code could link print to digital and digital to printed content through the use of smartphones to connect the researchers to related videos, articles, tables, and figures.

\section{QR CODES FOR ACADEMIC PUBLICATIONS}

Modern academic publishing is largely dependent on the use of the Internet and nowadays many scientists and researchers consult articles and books mostly in electronic or PDF format rather than hard copy. URL links make these valuable documents accessible and QR codes are scannable from a mobile device and both publishers and readers are enthusiastic to use QR codes. Eighty three percent of North American consumers are aware of Quick Response codes, and forty seven percent of those have ever used their camera phones to scan one. Among those who have scanned a code, near half did so from a periodical publication (49.8\%) [19][20].

The major factor which makes the use of this technology more likely to become commonplace in academic publishing is to enrich content with online materials especially in the cut in edge sciences, more visibility, more accessibility and gaining more credibility. Thus, assigning a QR code to a scientific journal and printing it on the cover or assigning it to each article can lead to enhance impact of researchers, journals, and increase success for more visibility, prestige, and citations [21][22].

\section{QR Codes for Academic Institutions}

Although QR codes are usually black and white, they do not evermore need to be. Also, much higher data density is another feature of the code. If designed correctly, they can contain images, logos, artworks and be colorful in any frame shape or background behind logos for branding and more visual attraction [23]. It means that customizing the QR codes are free of charge and possible. Nevertheless, they still covey the right information even though the layout is unconventional. Universities and research institutes can use QR code for their advertisement, marketing, Communication and many different things such as scientific annual congresses and awards. Conference organizers are placing them on bulletin boards to help attendees find their blogs and avenue easier. Also, broadly enhance participant engagement and facilitate administrative tasks in managing and training [24]. 


\section{QR CODES FOR REPUTATION OF SCIENTISTS}

There are many revolutionary ways to transform yourself from a researcher to a reputed niched scientist. One of the applicable important ways is increasing the visibility of your researches. After search engine optimization, using QR code could attract and encourage others to check the articles which have QR code. Therefore, I suggest you publish your scientific articles in the journals that use QR codes on their title page, the cover of the journal, websites, and marketing. Also, print QR code in your business card and your new future books as an up-to-date scientist.

\section{HOW TO CREATE QR CODES?}

The easiest way to create a matrix barcode is to use an online $\mathrm{QR}$ code generator. It usually takes three steps to make a static QR code. First, Choose the QR code type, then, enter the information, and finally generate the code. There are many online $Q R$ code creators on the internet.

\section{WHERE CAN USE QR CODES?}

Personal, Institutional and public use of QR codes are possible free of charge. These kinds of consumers could use it as Website URL, YouTube Video, Image File, PDF File, Google Maps Location, MP3, Twitter, Facebook, LinkedIn, Instagram, FourSquare, App Store Download, iTunes Link, Dropbox, Plain Text, Telephone Number, Skype Call, SMS Message, Email Address, Email Message, Contact Details, Digital Business Card, Attendance Tracking, Event (VCALENDAR), Vcard (provide immediate personal data interchange), Curriculum Vitae, on homepage banners, WiFi Login, PayPal Buy Now Link, Bitcoin, magazine advert and etc.[25]

\section{CONCLUSION}

So, scientific journal leaders should notice that QR code as a unique shaped matrix code is increasingly being used in cross-media marketing campaigns in many developed countries of the world. They are silently promoting their own scientific publications for more visualization and citations. This is one of the ways for the propaganda of the developed countries and prestigious publishers such as Elsevier to find their niche. A simple free tool that has been ignored by eastern scientific journals and academic institutes for many years. As the author checked English Iranian journals in the Iranian journals of medical sciences database belonged to the health ministry of Iran, no Iranian academic publication or publisher has and uses QR code or even barcode on their websites or on their journal covers till 16 Dec 2019. Although these are valuable scientific journals which indexed in Scopus, ISI, and PubMed [26] It shows that executive managers and editorial boards of Iranian academic journals do not aware of the importance of QR code and barcodes which are always used by international journals such as Nature.

\section{SOURCES OF FUNDING}

None.

\section{CONFLICT OF INTEREST}

None.

\section{ACKNOWLEDGMENT}

I would like to express my appreciation to Professor Hossein Baharvand, Professor Abdolhossein Shahverdi for their cooperation, information and spiritual support. The author has no conflict of interest and financial support. 
Utility and Impact of QR Codes and Barcodes in Scholarly Journals

\section{REFERENCES}

[1] QR Code development story: Denso Wave; [cited 2019]. Available from: https://www.densowave.com/en/technology/vol1.html.

[2] Japan Robot Association Japan [December 2019]. Available from: https://www.jara.jp/e/list/regular.html.

[3] History of QR Code [Dec 2019]. Available from: https://www.qrcode.com/en/history/.

[4] Woodford Chris. QR codes and 2D barcodes [Dec 2019]. Available from: https://www.explainthatstuff.com/how-data-matrix-codes-work.html.

[5] Peter Ian. So, who really did invent the Internet? [15 Dec 2019]. Available from: http://www.nethistory.info/History\%20of\%20the\%20Internet/origins.html.

[6] QR Code Generator [15 Dec 2019]. Available from: https://www.qrstuff.com/.

[7] Sager Ira. Before IPhone and Android Came Simon, the First Smartphone: Bloomberg News; June 29, 2012 [15 Dec 2019]. Available from: https://www.bloomberg.com/news/articles/2012-06-29/before-iphone-andandroid-came-simon-the-first-smartphone.

[8] Sharp J-SH04: World's First Ever Phone with Integrated Camera 2010 [15 Dec 2019]. Available from: https://gadgetizor.com/sharp-j-sh04-worlds-first-ever-phone-with-integrated-camera-pictures2001/5482/.

[9] Shintaro Okazaki Hairong Li, Morikazu Hirose. Benchmarking the Use of QR Code in Mobile Promotion: Three Studies in Japan. Journal of Advertising Research. March 2012;52(1):102.

[10] Soon Tan Jin. QR Code. synthesis journal. 2008.

[11] Kavanagh Duncan. Trends: Will QR Codes Make a Comeback in 2019? : Global Web Index; 17 Dec 2018 [16 Dec 2019]. Available from: https://blog.globalwebindex.com/trends/qr-codes-2019/.

[12] Hopkins David. QR code in education: QR Codes ... A great way to pass information from on source to another: from teacher to student, from student to student, and even from student to teacher! 1st Edition. ed: CreateSpace Independent Publishing Platform; 2013.

[13] USING QR CODES IN THE CLASSROOM TO ENHANCE LEARNING: What I have Learned; [15 Dec 2019$].$ Available from: https://www.whatihavelearnedteaching.com/using-qr-codes-in-the-classroom/.

[14] 44 QR Codes Resources for Teaching \& Learning: Teach Thought; 16 June 2016 [15 Dec 2019]. Available from: https://www.teachthought.com/technology/44-qr-codes-resources-for-teaching-and-learning/.

[15] Kankaanranta Jenni Rikala and Marja. BLENDING CLASSROOM TEACHING AND LEARNING WITH QR CODES. 2014.

[16] Lee J-K Lee I-S Kwon Y-J. Scan Scan \& Learn! Use of Quick Response Codes \& Smartphones in a Biology Field Study. Am Biol Teach. 2011; 73:485-92.

[17] Coleman Jason. QR Codes: What Are They and Why Should You Care? Kansas Library Association College and University Libraries Section Proceedings. 2011;1(1).

[18] DA MacRae. Introducing QR. Codes: linking print and digital content viasmartphone. Neurosurgery. 2011; 68:854-5.

[19] International Brand Spark. 2013 [16 Dec 2019]. Available from: https://www.brandspark.com/.

[20] Data Dive: QR Codes: Marketing Charts; 8 July 2013 [16 Dec 2019]. Available from: https://www.marketingcharts.com/digital-29525.

[21] Lotfipanah M. Does Search Engine Optimisation (SE0) Increase Scientific Journals' Visibility, Prestige, and Impact Factor as a New Method? International Journal of Knowledge Management and Practices. 2016;4(1):51-3.

[22] Lotfipanah M. Enhance Impact of Researchers, Journals and Increase Success for More Citations. Trends in Information Management 2017;11(2):174-200.

[23] Sentance Rebecca. The pros and cons of QR codes 18 April 2019 [cited 16 Dec 2019]. Available from: https://econsultancy.com/the-pros-and-cons-of-qr-codes/.

[24] Chiraag Thakrar Karia corresponding author Andrew Hughes, and Sue Carr. Uses of quick response codes in healthcare education: a scoping review. BMC Med Educ. 2019;19(1):456.

[25] QR Stuff: QR Code Generator, Inc.; 2017 [16 Dec 2019]. Available from: https://www.qrstuff.com/.

[26] Iranian journals of medical sciences database. [cited 16 Dec 2019]. Available from: http://journals.research.ac.ir/isi\#. 